\title{
Electropolishing of Carbon Steel in Presence of Some Natural Polymers under Natural and Forced Convection Conditions
}

\author{
Hamdy. F.M. El-shamy ${ }^{1}$, Y. A. Aggour ${ }^{1}$, Mervette El-batouti ${ }^{2}$, A. M. Ahmed ${ }^{2}$ \\ ${ }^{I}$ Department of Chemistry, Faculty of Science, Damietta University, Egypt \\ ${ }^{2}$ Department of Chemistry, Faculty of Science, Alexandria University, Egypt
}

*Corresponding Author: Hamdy. F.M. El-shamy, Department of Chemistry, Faculty of Science, Damietta University, Egypt

\begin{abstract}
The effect of some natural polymers on the rate of electropolishing of carbon steel in phosphoric acid was studied by measuring the limiting current of its anodic dissolution. It is found that the rate of electropolishing increased by decreasing $\mathrm{H}_{3} \mathrm{PO}_{4}$ concentration and electrode height. Natural polymers were found to inhibit the process of electropolishing; the inhibition efficiency increased with increasing concentration of the investigated compounds at a fixed temperature, but decreases with increasing temperature. Values of activation energy indicate that the reaction is diffusion controlled. The adsorption isotherm Flory- Huggins and Kinetic are applied. The values of free energy of adsorption $\left(\Delta G_{\text {ads }}\right)$ obtained indicate the spontaneous adsorption of the inhibitor. The overall mass transfer correlations under the present conditions were obtained using the method of dimensional analysis. The results agreed with the previous studies of mass transfer to rotating cylinder in turbulent flow. The morphology of the polished specimens was monitored using Scanning Electron Microscope (SEM). SEM examination of the carbon steel surface revealed that these compounds inhibited carbon steel from corrosion by adsorption on its surface to form protective film. The presence of these organic compounds on the electrode surface was confirmed by SEM investigations.
\end{abstract}

Keywords: Electropolishing of carbon steel, Natural polymers, Limiting Current,Thermodynamic parameters and adsorption isotherm

\section{INTRODUCTION}

Electropolishing is a surface finishing process by which a metal surface is made smooth and bright by making it an anode in an appropriate electrolytic solution $[\mathbf{1 , 2}$. Electropolishing is suitable for polishing of hardened materials that are mechanically difficult to machine, because in electropolishing the electrode and the work piece are not in contact with each other.

The earliest explanations of electropolishing were given by Jacquet and Elmore. Jacquet attributed electropolishing to the formation of a viscous layer on the workpiece [1]. The non-uniform thickness of the viscous layer over the material surface results in a different ohmic resistance from the cathode to the anode. This cause greater dissolution of the protruded parts compared to the depressed part, thus creating a uniform surface profile. This explanation was later challenged by Elmore who studied the current-voltage relationship for the polishing of copper in orthophosphoric acid system. He attributed the polishing effect to a varying concentration gradient of the dissolved metal ions over the protrusions and valleys [3].

Carbon steel is widely used in many applications in structural steel to build buildings and bridges. It is also used for parts in consumer products like automobiles, refrigerators and washing machines, Ships, pipe lines, heat conductors, heat exchangers, etc [4-8].

So far the majority of previous studies on electropolishing have been conducted in blank solutions (without organic additives).Organic additives especially polymers could affect the rate of electropolishing through interfering with the charge transfer step or the mass transfer step $[\mathbf{9 , 1 0 ]}$.

Natural polymers containing polar groups and heterocyclic compounds with polar functional groups and conjugated double bonds have been reported to inhibit carbon steel corrosion [11-15]. The inhibiting action of these natural polymers is usually attributed to their interaction with carbon steel 
surface via their adsorption. Polar functional groups are regarded as the reaction center that stabilizes the adsorption process. In general, the adsorption of inhibitor on metal surface depends on the nature and the surface charge of the metal, the adsorption mode, its chemical structure and the type of electrolyte solution [15]. The aim of the present work is to study the effect of natural polymers namely starch, gelatin, agar, chitosan, cellulose acetate, cellulose and carboxymethyl cellulose sodium salt on the rate of electropolishing of carbon steel. Such investigation included changes in temperature; speed of rotation cylinder (RCE) and concentration of organic compounds Physical properties of solution such as density, viscosity and diffusion coefficient are studied to obtain a dimensionless correlation among all these parameters. The morphology of the specimens after experiment is monitored using Scanning Electron Microscope (SEM). The study of the (SEM) to graphs support the experimental measurements and give more light on carbon steel surface.

\section{EXPERIMENTAL}

AnalaR grade $\mathrm{H}_{3} \mathrm{PO}_{4}(98 \% \mathrm{w} / \mathrm{w})$ and double distilled water used to prepare the electrolyte. Natural polymers were used in this work are starch, gelatin, agar, chitosan, Arabic gum, cellulose acetate, cellulose and carboxymethyl cellulose sodium salt (CMC).

\subsection{Measurements of Limiting Current}

Polarization curves were obtained by increasing the cell current step wise and measuring the steady state anode potential against a reference electrode which consisted of a wire immersed in a cup of Luggin tube filled with phosphoric acid concentration similar to that in the cell, the cell used is undivided cell (without diaphragm), the tip of the Luggin tube was placed 0.5-from the anode. The potential difference between the anode and the reference was measured by high impedance potentiometer. Five phosphoric acid concentrations $(4,6,8,10$, and $12 \mathrm{M})$ were prepared from Analar grade phosphoric acid distilled water. The anode height varied from 1-5 cm. Before each run, the back part of the anode was insulated with polystyrene lacquers and the active surface of the anode was polished with fin emery paper, degreased with trichloroethylene, washed with alcohol and finally rinsed in distilled water. Electrode treatment was similar to that used by Wilke [16]. Organic acid concentration were $100-800 \mathrm{ppm}$. The rate of electropolishing of copper was determined at $25^{\circ} \mathrm{C}$.

\subsection{Rotating Cylinder Electrode (R.C.E.) Cell and Circuit}

The shaft was driven by a variable speed motor. The frequency of rotation, recorded as revolution per minute-, was counted by an optical tachometer. The glass vessel which holds electrolyte is $13 \mathrm{~cm}$ diameter. The electrical circuit consists of 6 volts D.C. power supply, a multirange ammeter connected in series with the cell to measure the current, and voltmeter is connected in parallel with the cell to measure its voltage.

The anode consists of a carbon steel metal cylinder $1 \mathrm{~cm}$ diameter and $3 \mathrm{~cm}$ length. The flat bottom of the cylinder as well as the drive shaft were insulated by epoxy- resin. The cathode is made of a cylinder carbon steel metal electrode of $12 \mathrm{~cm}$ diameter; it's also acted as the reference electrode by virtue of its high surface area compared to that of the anode.

\subsection{Density and viscosity measurements}

The density was measured by using DA-300 Kyoto electronics density measurement equipment at different temperatures. The viscosity was measured by using Koehler viscosity Bath (Model K23400 Kinematic bath) at different temperatures.

\section{RESULTS AND DISCUSSION}

Figure(1) shows a typical polarization curves obtained using different concentration of starch at $25^{\circ} \mathrm{C}$ and $8 \mathrm{M} \mathrm{H}_{3} \mathrm{PO}_{4}$ at $3 \mathrm{~cm}$ height for undivided cell. The curve consists of three parts: in the first part, the current density is proportional to the voltage. At the second part of the curve, the metal undergoes electropolishing. The limiting current at which polishing take place was determined from those polarization curves and used to calculate the mass transfer coefficient $(\mathrm{K})$ of carbon steel polishing in $\mathrm{H}_{3} \mathrm{PO}_{4}$ from the equation:

$\mathbf{K}=\mathbf{I} / \mathbf{z F C}_{\mathbf{0}}$

$\mathrm{C}_{\mathrm{o}}$ : bulk concentration, z: valence and F: Faraday number. 


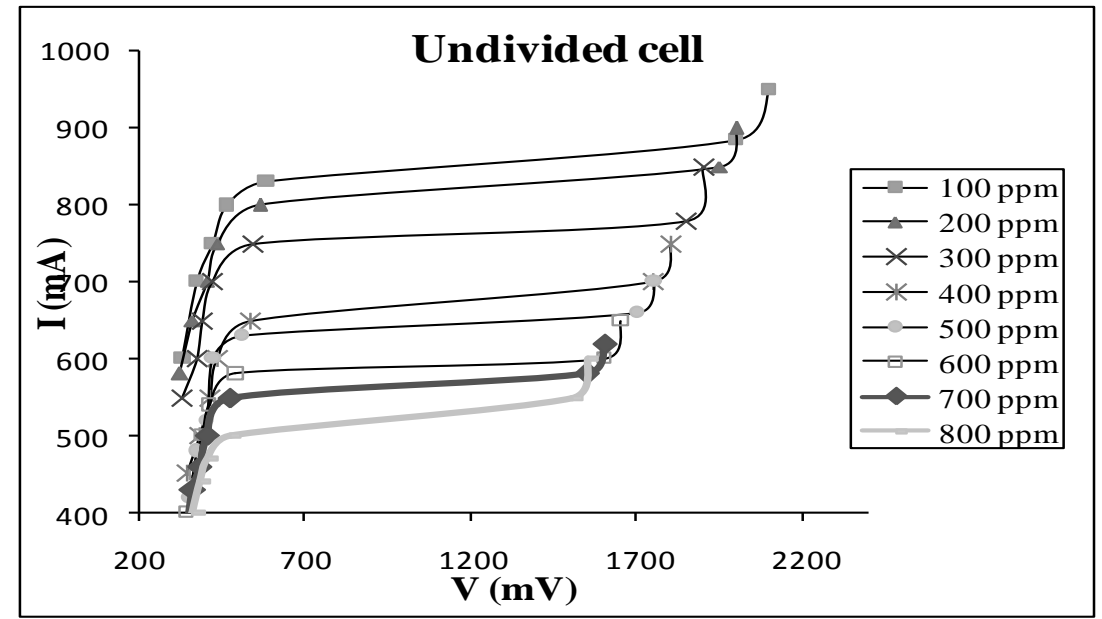

Figure1. The relation between $I(m A)$ and $V(m V)$ in presence of different concentration of starch at $25^{\circ} \mathrm{C}$ and 8 $\mathrm{M} \mathrm{H}_{3} \mathrm{PO}_{4}$ at $3 \mathrm{~cm}$ height for undivided cell

\subsection{Effect of Electrode Height on Limiting Current}

Figure (2) show that, the limiting current density decreases with the increase in height. In electropolishing and generally for anodic dissolution of metal, the direction of flow of the hydrodynamic boundary layer and the diffusion layer increase in the downward direction, i.e. the resistance to mass transfer increases in the downward direction. Accordingly, the local limiting current density increases in the up-ward direction of the anode. This explains why polishing is attained at the upper parts of the electrode before the lower parts at the limiting current region. This was confirming by visual observation during electropolishing. The average limiting current density decreases with increase in the height according to the equation [17]:

$I_{L} \propto 1 / H$

Where $\mathbf{H}$ is the height of electrode

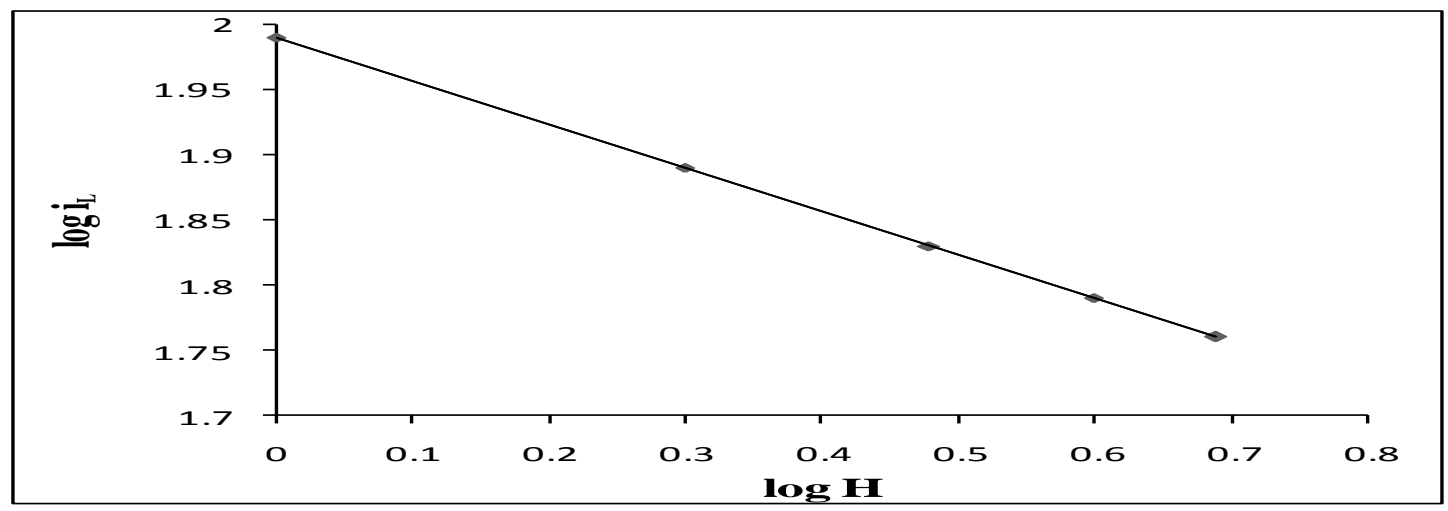

Figure2. The relation between current density and height at $25^{\circ} \mathrm{C}$ and $8 \mathrm{M} \mathrm{H}_{3} \mathrm{PO}_{4}$

\subsection{Effect of Electrolyte Concentration on Limiting Current}

Figure 3 shows the limiting current decreases with increasing phosphoric acid concentration within the range studied $(4-12 \mathrm{M})$ at $25^{\circ} \mathrm{C}$. This is agreement with the finding of the other authors who worked within the same range of concentration [18]. The decrease in the limiting current with $\mathrm{H}_{3} \mathrm{PO}_{4}$ concentration is attributed two effects: (a)The solubility of dissolved ferrous phosphate in ortho phosphoric acid, which is responsible for the limiting current, decreases with increasing phosphoric acid concentration. (b)The viscosity of the solution increases with increasing $\mathrm{H}_{3} \mathrm{PO}_{4}$ concentration with consequence decrease in the diffusivity of $\mathrm{Fe}^{+2}$ according to Stokes-Einstein equation [19].

D $\eta / T=$ constant

Where, $\mathrm{D}$ is the diffusivity of $\mathrm{Fe}^{+2}\left(\mathrm{~cm}^{2} \mathrm{~S}^{-1}\right), \eta$ is the viscosity of the solution (poise), and $\mathrm{T}$ is the absolute temperature. 


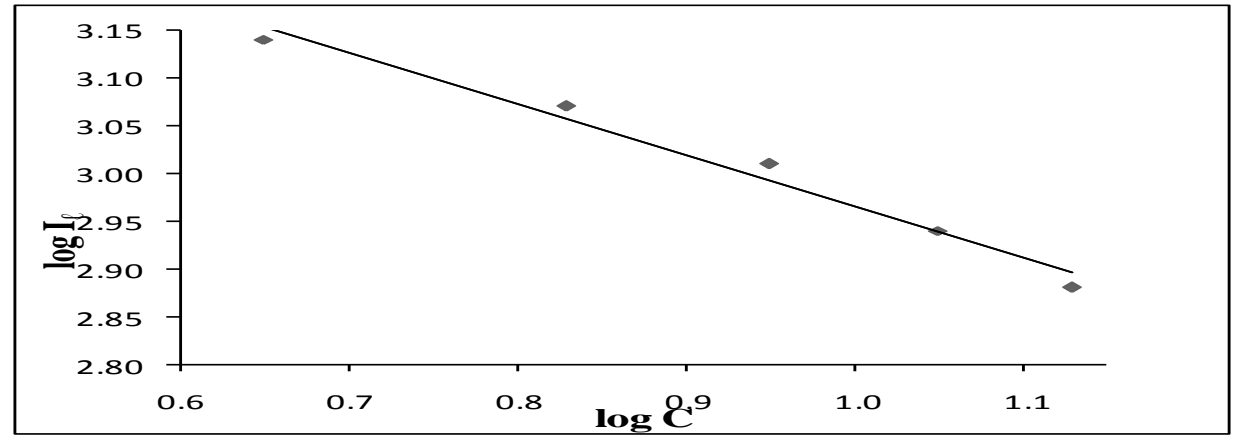

Figure3. The relation between current density and $\mathrm{H}_{3} \mathrm{PO}_{4}$ concentrations for at $25^{\circ} \mathrm{C}$ and $3 \mathrm{~cm}$ height

\subsection{Effect of Organic Compounds Concentration on the Limiting Current}

The rate of electropolishing, which is represented by the anodic limiting current, decreases with increasing concentration of natural polymers compounds and increases with temperature.

The inhibition efficiency of the polymer on the rate of polishing is given by the equation:

$$
\% \text { Inhibition }=(\mathbf{I}-\mathbf{I} / \mathbf{I}) \times \mathbf{1 0 0}
$$

Where $\mathbf{I}$ is limiting current without inhibitor, $\mathbf{I}^{\mathbf{o}}$ is limiting current with inhibitor.

Table (1) and Figure (4) shows that the percent inhibition caused by natural polymers ranges from 3.87 to $61.54 \%$ depending on the natural polymers composition, concentration, temperature and type of cell [25].

The following order of decreasing in percent inhibition was observed:

Cellulose acetate $>$ CMC $>$ Chitosan $>$ Cellulose $>$ Arabic gum $>$ Starch $>$ Agar $>$ Gelatin

The results also suggest that in case of (Gelatin, Agar) the adsorption of the inhibitor is weaker and the adsorption of the inhibitor takes place [20]. For Cellulose acetate and to a certain extent for Starch also, the adsorption bonds appear to be stronger and resist the adsorption.

Table1. The relation between percentage inhibition and concentration of all compounds at different temperatures

\begin{tabular}{|c|c|c|c|c|c|c|c|c|}
\hline \multirow[t]{3}{*}{$\mathbf{C}(\mathbf{p p m})$} & \multicolumn{8}{|c|}{ Percentage inhibition (\%) } \\
\hline & \multicolumn{4}{|c|}{ Starch } & \multicolumn{4}{|c|}{ Arabic gum } \\
\hline & $25^{\circ} \mathrm{C}$ & $30^{\circ} \mathrm{C}$ & $35^{\circ} \mathrm{C}$ & $40^{\circ} \mathrm{C}$ & $25^{\circ} \mathrm{C}$ & $30^{\circ} \mathrm{C}$ & $35^{\circ} \mathrm{C}$ & $40^{\circ} \mathrm{C}$ \\
\hline 100 & 13.23 & 11.54 & 9.68 & 8.85 & 14.70 & 10.77 & 12.26 & 11.46 \\
\hline 200 & 16.67 & 19.23 & 16.13 & 14.06 & 21.57 & 21.54 & 19.35 & 16.67 \\
\hline 300 & 23.53 & 23.08 & 22.58 & 19.27 & 29.41 & 26.92 & 25.81 & 21.87 \\
\hline 400 & 31.37 & 30.77 & 29.03 & 24.48 & 33.33 & 34.61 & 32.26 & 27.08 \\
\hline 500 & 35.29 & 33.08 & 35.48 & 32.29 & 39.21 & 38.46 & 38.71 & 34.89 \\
\hline 600 & 41.18 & 38.46 & 41.93 & 37.50 & 44.12 & 42.31 & 45.16 & 40.10 \\
\hline 700 & 43.14 & 42.31 & 45.16 & 40.10 & 48.04 & 46.15 & 48.39 & 45.31 \\
\hline \multirow[t]{2}{*}{800} & 46.09 & 46.15 & 48.39 & 42.71 & 50.98 & 50.77 & 51.61 & 47.92 \\
\hline & \multicolumn{4}{|c|}{ Gelatin } & \multicolumn{4}{|c|}{ Cellulose acetate } \\
\hline 100 & 6.86 & 4.61 & 3.87 & 6.25 & 26.47 & 26.92 & 25.81 & 21.87 \\
\hline 200 & 11.76 & 11.54 & 9.68 & 8.85 & 31.37 & 30.77 & 29.03 & 27.08 \\
\hline 300 & 15.69 & 15.38 & 12.90 & 14.06 & 36.27 & 35.38 & 36.77 & 32.29 \\
\hline 400 & 21.57 & 20.77 & 16.13 & 16.67 & 41.18 & 40.00 & 41.93 & 37.50 \\
\hline 500 & 26.47 & 23.85 & 19.35 & 19.27 & 45.10 & 46.15 & 45.16 & 42.71 \\
\hline 600 & 30.39 & 26.92 & 22.58 & 21.87 & 50.98 & 52.31 & 51.61 & 47.92 \\
\hline 700 & 33.33 & 30.77 & 25.81 & 24.48 & 56.86 & 55.38 & 56.13 & 53.12 \\
\hline \multirow[t]{2}{*}{800} & 36.27 & 33.85 & 29.03 & 29.69 & 60.78 & 61.54 & 58.06 & 55.21 \\
\hline & \multicolumn{4}{|c|}{ Agar } & \multicolumn{4}{|c|}{ Cellulose } \\
\hline 100 & 11.76 & 7.69 & 6.45 & 6.25 & 17.65 & 18.46 & 16.13 & 14.06 \\
\hline 200 & 17.65 & 15.38 & 12.90 & 11.46 & 22.55 & 23.08 & 22.58 & 21.87 \\
\hline
\end{tabular}


Electropolishing of Carbon Steel in Presence of Some Natural Polymers under Natural and Forced Convection Conditions

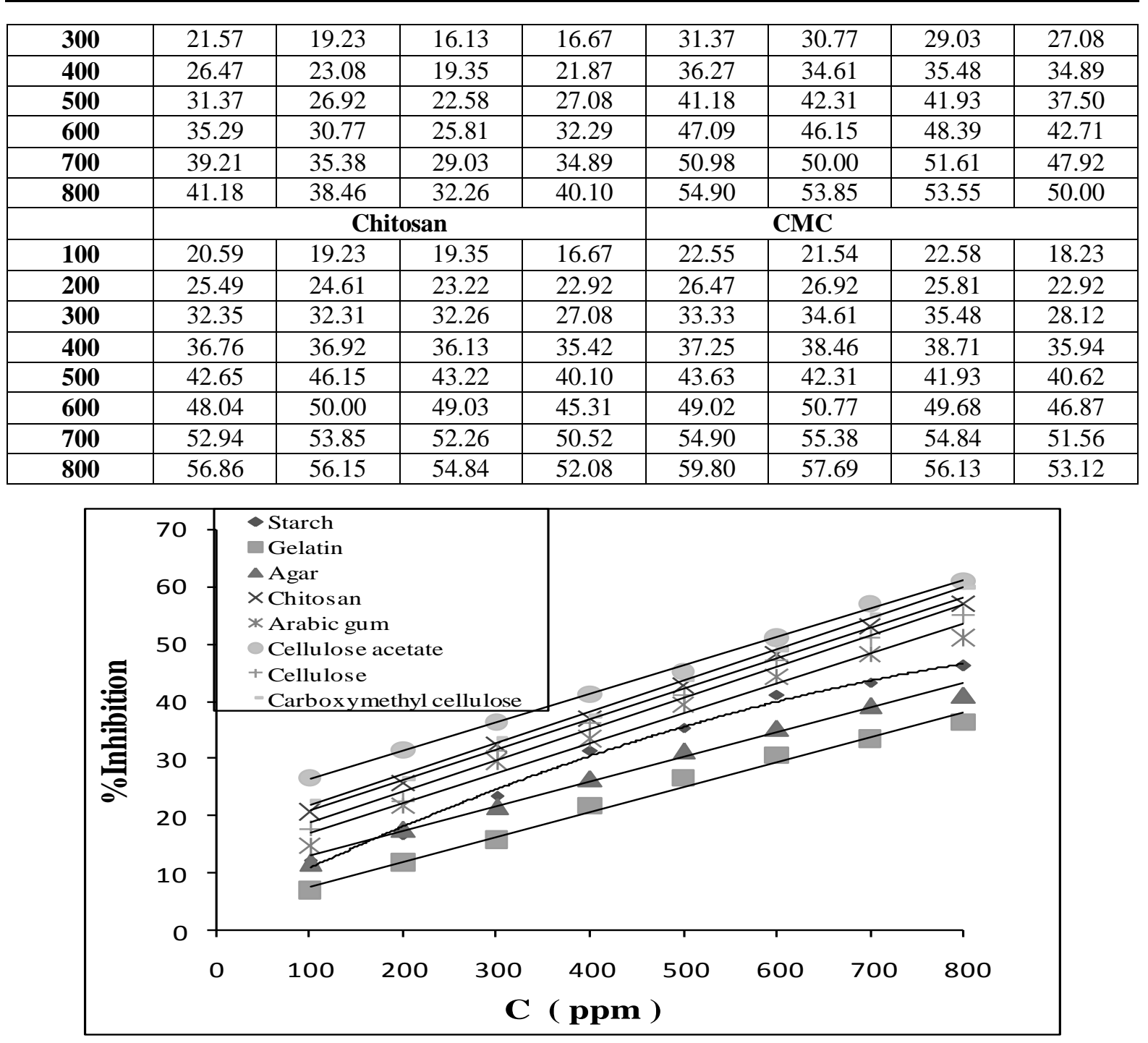

Figure4. The relation between \% inhibition and concentration of all natural polymers at $25^{\circ} \mathrm{C}$

\subsection{Adsorption Isotherm}

It generally assumed that the adsorption isotherm of the inhibitor at the metal solution interface is the first main role the mechanism of inhibitors action in aggressive acid media.

The degree of surface coverage $\Theta$ at constant temperature was determined from this equation:

$\boldsymbol{\theta}=\mathbf{I}-\mathbf{I} / \mathbf{I}$

Data related to the degree of surface coverage $(\Theta)$ were tested graphically in order to determine the most suitable adsorption isotherm.

The Flory-Hugins adsorption isotherm is applied to investigate the adsorption mechanism by the following equation [21].

$\log \Theta / C=\log x K+x \log (1-\theta)$

The Flory-Huggins adsorption isotherm for carbon steel electrode in $\mathrm{H}_{3} \mathrm{PO}_{4}$ plotted as $\log \mathrm{\Theta} / \mathrm{C}$ against $\log (1-\Theta)$ at $25^{\circ} \mathrm{C}$. A straight line is obtained with a slope $\mathrm{x}$ and intercept $\log \mathrm{xK}$.

Where $\mathrm{x}$ is the number of inhibitor molecules occupying one active site or the number of water molecules replaced by one molecule of inhibitor, $\mathrm{K}$ is the equilibrium constant of adsorption process. It is clear that, the surface coverage data are useful for discussing adsorption characteristics. The adsorption of inhibitors at metal solution interface may be due to the formation of either electrostatic or covalent bonding between the adsorbents and the metal surface atoms [22].

The kinetic adsorption isotherm may be written in the form [23]: 
$\log \boldsymbol{\theta} / 1-\boldsymbol{\theta}=\log \mathrm{k}^{\prime}+\mathbf{y} \log \mathrm{C}$

Where $\mathrm{y}$ is the number of inhibitor molecules occupy one active site. The binding constant of adsorption $\mathrm{K}=\mathrm{k}^{\prime}(1 / \mathrm{y})$, where $1 / \mathrm{y}$ is the number of the surface active sites occupied by one molecule of the inhibitor, and $\mathrm{k}^{\prime}$ is the binding constant. linear relation of the inhibitor molecules between $\log \Theta$ $/ 1-\mathrm{O}$ and $\log \mathrm{C}$ at $25^{\circ} \mathrm{C}$ is obtained, and the calculated values of $1 / \mathrm{y}$ and $\mathrm{K}$ given in Table 2.

The values of 1/y depend on the type of natural polymers. From Table 3 it is obvious that, the value of $1 / \mathrm{y}$ for Gelatin is approximately one. Suggesting that, the compound attached to one active site per inhibitor molecule.

For other inhibitors (Starch, Agar, Chitosan, Arabic gum, Cellulose acetate, Cellulose, CMC) the Values of 1/y higher than one, indicating that, the given inhibitors Molecules are attached to more one active site.

The free energy of adsorption $\left(\Delta \mathrm{G}_{\mathrm{ads}}\right)$ at different Concentration was calculating from the following equation [21, 24]:

$\Delta \mathbf{G}_{\text {ads }}=-$ RTIn $(55.5 \mathrm{~K})$

The value 55.5 is the concentration of water in the Solution mol/1 $[\mathbf{2 5}, \mathbf{2 6}]$.

The values of $\Delta \mathrm{G}_{\text {ads }}$ are given in Table 3. In all cases, the $\Delta \mathrm{G}_{\mathrm{ads}}$ values are negative and lie in the rank of $9.12-11.86 \mathrm{KJ} / \mathrm{mol}$. the most efficient inhibitor shows the most negative value. This suggests that, they strongly adsorbed on the metal surface. The negative values of $\Delta \mathrm{G}_{\mathrm{ads}}$ indicate that, the spontaneous adsorption of the inhibitor. It's found that, the $\Delta \mathrm{G}_{\mathrm{ads}}$ values are more positive than - 40 K.J/mol indicating that the inhibitors are physically adsorbed on the metal surface. Similar results also had been reported [27].

Table2. The values of $k, x$ and $1 / y$ of phosphoric acid in presence of different phenols derivatives to FloryHuggins and Kinetic adsorption isotherm

\begin{tabular}{|c|c|c|c|c|c|}
\hline \multirow{2}{*}{ Compounds } & \multicolumn{2}{|c|}{ Flory-Huggins } & \multicolumn{3}{c|}{ Kinetic adsorption isotherm } \\
\cline { 2 - 6 } & $\mathrm{X}$ & $\mathrm{K}$ & $\mathrm{Y}$ & $1 / \mathrm{y}$ & $\mathrm{k}$ \\
\hline Staech & 1.235 & 1.001 & 0.896 & 1.116 & 1.137 \\
\hline Gelatin & 0.862 & 0.781 & 1.008 & 0.992 & 0.699 \\
\hline Agar & 1.742 & 0.716 & 0.816 & 1.225 & 0.996 \\
\hline Chitosan & 1.442 & 1.462 & 0.797 & 1.255 & 1.724 \\
\hline Arabic gum & 1.351 & 1.181 & 0.880 & 1.136 & 1.376 \\
\hline Cellulose acetate & 1.639 & 1.813 & 0.700 & 1.429 & 2.162 \\
\hline Cellulose & 1.303 & 1.374 & 0.863 & 1.159 & 1.563 \\
\hline CMC & 1.333 & 1.608 & 0.791 & 1.264 & 1.840 \\
\hline
\end{tabular}

Table3. The values of free energy of adsorption $\left(\mathrm{kJ}^{\mathrm{m}} \mathrm{mol}^{-1}\right)$ of phosphoric acid in presence of different phenols derivatives using different methods

\begin{tabular}{|c|c|c|}
\hline \multirow{2}{*}{ Compounds } & \multicolumn{2}{|c|}{$-\Delta \mathrm{G}_{\text {ads }}\left(\mathrm{K}_{\text {.J. }} \mathrm{mol}^{-1}\right)$} \\
\cline { 2 - 3 } & Flory-Huggins & Kinetic adsorption isotherm \\
\hline Staech & 9.95 & 10.27 \\
\hline Gelatin & 9.34 & 9.06 \\
\hline Agar & 9.12 & 9.94 \\
\hline Chitosan & 10.89 & 11.30 \\
\hline Arabic gum & 10.36 & 10.74 \\
\hline Cellulose acetate & 11.42 & 11.86 \\
\hline Cellulose & 10.74 & 11.06 \\
\hline CMC & 11.13 & 11.46 \\
\hline
\end{tabular}

\subsection{Effect of temperature on the performance of inhibitors}

The effect of temperature on the copper electropolishing rate in absence and presence of phenols derivatives was determined in the temperature range $25,30,35,40^{\circ} \mathrm{C}$ and illustrated in Table 1 . It observed that the electropolishing rate increases with temperature for different concentrations of organic compounds. 


\subsection{Thermodynamic Treatment of the Results}

From the integrated form of the Arrhenius equation [28-30]:

$\ln \mathrm{I}=-\mathrm{E}_{\mathrm{a}} / \mathbf{R T}+\ln \mathrm{A}$

Where $\mathrm{R}$ is the gas constant $\left(8.314 \mathrm{kJmol}^{-1}\right), \mathrm{E}_{\mathrm{a}}$ is the activation energy and $\mathrm{A}$ is the frequency factor. It can be seen that, the gradient is given by $-\mathrm{E}_{a} / \mathrm{R}$ and the intercept by in A. Figure. 6 give the values of $\mathrm{E}_{\mathrm{a}}$ for the Starch as example.

The values for enthalpy of activation $\Delta \mathrm{H}^{*}$, entropy of activation $\Delta \mathrm{S}^{*}$, and free energy of activation $\Delta \mathrm{G}^{*}$ can be obtaining by using equations:

$\Delta \mathbf{H}^{*}=\mathbf{E}_{\mathbf{a}}-\mathbf{R T}$

$\Delta \mathrm{S}^{*} / \mathrm{R}=\ln \mathrm{A}-\ln (\mathrm{kTe} / \mathrm{h})$

$\Delta \mathbf{G}^{*}=\Delta \mathbf{H}^{*}-\mathbf{T} \Delta \mathbf{S}^{*}$

Where $\mathrm{k}$ is Boltzmann's constant, $\mathrm{e}=2.7183, \mathrm{~h}$ is Plank's constant, $\mathrm{A}$ is Arrhenius constant, $\mathrm{T}$ is absolute temperature and $\mathrm{R}$ is the universal gas constant. The adsorption is usually followed by liberation of heat of adsorption, so that $\mathrm{E}_{\mathrm{a}}<0$, consequently the rate of adsorption decreases with temperature and as a result, the surface coverage at given concentration decreases with increasing temperature.

The results showed positive sign for Ea, reflecting the endothermic nature of electrodeposition process. It is obviously seen that the Ea values for inhibited systems are higher that Ea for uninhibited system. This indicates that physical adsorption occurred in the first stage, which explains the nature of organic molecules - metal interaction. On the other hand, physical adsorption is related to lower values of $\mathrm{Ea}(<43 \mathrm{~kJ} . \mathrm{mol}-1)$, also indicating that the diffusion processes are controlling the electropolishing reaction [29-32].

Table 4 show that the results show positive sign for $\Delta \mathrm{H}^{*}$, reflecting the endothermic nature of the adsorption process. The negative values of $\Delta \mathrm{S}^{*}$ pointed to a greater order produced during the process of activation. This can achieved by the formation of activated complex represents association or fixation with consequent loss in the degree of freedom of the system during the process. $\Delta \mathrm{G}^{*}$ values show limited increase with rise in the concentration of organic additives i.e.: $\Delta G^{*}$ values of the inhibited systems were more positive than that for the uninhibited systems revealing that in cores of inhibitor addition the activated electrodeposition complex becomes less stable as compared to its absence [30,32].

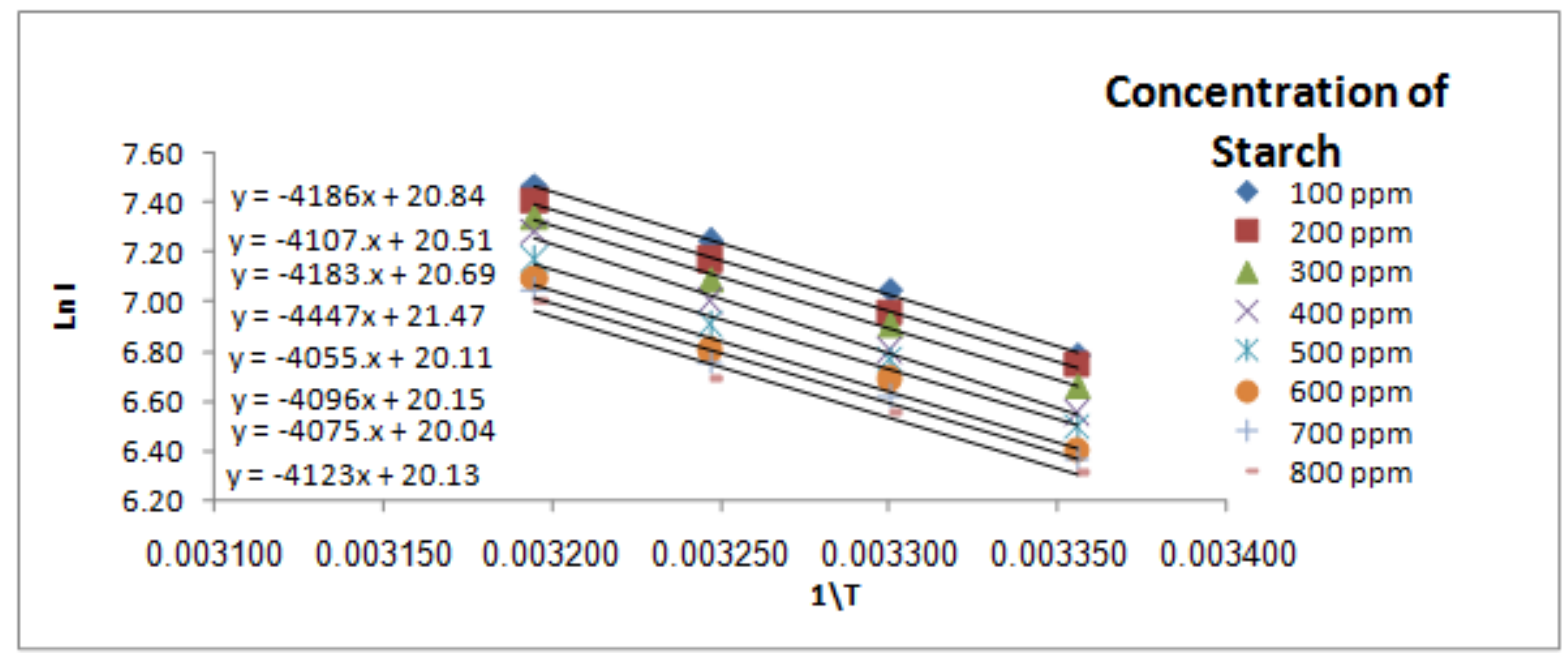

Figure6. Arrhenius plot at $25^{\circ} \mathrm{C}$ for different concentration of Starch 
Electropolishing of Carbon Steel in Presence of Some Natural Polymers under Natural and Forced Convection Conditions

Table4. The thermodynamic parameters at $25^{\circ} \mathrm{C}$ for $8 \mathrm{M} \mathrm{H}_{3} \mathrm{PO}_{4}, 3 \mathrm{~cm}$ height at different concentrations of natural polymers

\begin{tabular}{|c|c|c|c|c|c|c|c|c|}
\hline \multirow[t]{3}{*}{$\mathrm{C}(\mathrm{ppm})$} & \multicolumn{8}{|c|}{ Themodynamic parameters } \\
\hline & \multicolumn{4}{|c|}{ Starch } & \multicolumn{4}{|c|}{ Arabic gum } \\
\hline & $\begin{array}{c}\mathrm{E}_{\mathrm{a}} \\
\mathrm{kJ} \mathrm{mol}^{-1}\end{array}$ & $\begin{array}{c}\Delta \mathbf{H}^{*} \\
\mathrm{~kJ} \mathrm{~mol}^{-1}\end{array}$ & $\begin{array}{r}-\Delta \mathbf{S}^{*} \\
\mathbf{J}_{\mathbf{1}^{\prime}} \mathbf{m o l}^{-1}\end{array}$ & $\begin{array}{c}\Delta \mathrm{G}^{*} \\
\mathbf{k J} \mathrm{mol}^{-1}\end{array}$ & $\begin{array}{c}\mathrm{E}_{\mathrm{a}} \\
\mathrm{kJ} \mathrm{mol}^{-1}\end{array}$ & $\begin{array}{c}\Delta \mathbf{H}^{*} \\
\mathbf{k J} \mathrm{mol}^{-1}\end{array}$ & $\begin{array}{r}-\Delta \mathbf{S}^{*} \\
\mathbf{J}_{\mathbf{1}} \mathbf{m o l}^{-1}\end{array}$ & $\begin{array}{c}\Delta \mathbf{G}^{*} \\
\mathbf{k J} \mathbf{m o l}^{-1}\end{array}$ \\
\hline 0.00 & 32.17 & 29.69 & 86.85 & 55.57 & 32.17 & 29.69 & 86.85 & 55.57 \\
\hline 100 & 34.80 & 32.32 & 79.20 & 55.9 & 33.66 & 31.18 & 83.11 & 55.95 \\
\hline 200 & 34.14 & 31.66 & 81.94 & 56.08 & 35.39 & 32.91 & 78.12 & 56.19 \\
\hline 300 & 34.78 & 32.30 & 80.45 & 56.28 & 37.11 & 34.63 & 73.21 & 56.45 \\
\hline 400 & 36.97 & 34.49 & 73.96 & 56.53 & 36.82 & 34.34 & 74.79 & 56.63 \\
\hline 500 & 33.71 & 31.23 & 85.27 & 56.64 & 35.25 & 32.77 & 80.69 & 56.82 \\
\hline 600 & 34.05 & 31.57 & 84.93 & 56.88 & 34.54 & 32.06 & 83.77 & 57.02 \\
\hline 700 & 33.88 & 31.40 & 85.85 & 56.98 & 33.85 & 31.37 & 86.60 & 57.18 \\
\hline \multirow[t]{2}{*}{800} & 34.28 & 31.80 & 85.02 & 57.14 & 34.68 & 32.20 & 84.44 & 57.36 \\
\hline & \multicolumn{4}{|c|}{ Gelatin } & \multicolumn{4}{|c|}{ Cellulose acetate } \\
\hline 0.00 & 32.17 & 29.69 & 86.85 & 55.57 & 32.17 & 29.69 & 86.85 & 55.57 \\
\hline 100 & 32.60 & 30.12 & 85.93 & 55.73 & 35.18 & 32.70 & 79.45 & 56.38 \\
\hline 200 & 33.99 & 31.51 & 81.78 & 55.88 & 35.36 & 32.88 & 79.36 & 56.53 \\
\hline 300 & 33.48 & 31.00 & 83.85 & 55.99 & 34.61 & 32.13 & 82.52 & 56.72 \\
\hline 400 & 35.87 & 33.39 & 76.45 & 56.17 & 34.44 & 31.96 & 83.69 & 56.90 \\
\hline 500 & 37.41 & 34.93 & 71.80 & 56.33 & 34.39 & 31.91 & 84.52 & 57.10 \\
\hline 600 & 38.46 & 35.98 & 68.72 & 56.46 & 35.15 & 32.67 & 83.02 & 57.41 \\
\hline 700 & 39.03 & 36.55 & 67.23 & 56.59 & 35.72 & 33.24 & 81.94 & 57.66 \\
\hline \multirow[t]{2}{*}{800} & 37.85 & 35.37 & 71.47 & 56.67 & 39.67 & 37.19 & 69.72 & 57.97 \\
\hline & \multicolumn{4}{|c|}{ Agar } & \multicolumn{4}{|c|}{ Cellulose } \\
\hline 0.00 & 32.17 & 29.69 & 86.85 & 55.57 & 32.17 & 29.69 & 86.85 & 55.57 \\
\hline 100 & 35.20 & 32.72 & 77.62 & 55.85 & 34.56 & 32.08 & 80.53 & 56.08 \\
\hline 200 & 35.99 & 33.51 & 75.62 & 56.05 & 32.65 & 30.17 & 87.43 & 56.23 \\
\hline 300 & 35.58 & 33.10 & 77.37 & 56.16 & 35.36 & 32.88 & 79.36 & 56.53 \\
\hline 400 & 35.75 & 33.27 & 77.29 & 56.30 & 32.97 & 30.49 & 87.84 & 56.67 \\
\hline 500 & 35.94 & 33.46 & 77.12 & 56.44 & 35.03 & 32.55 & 81.86 & 56.95 \\
\hline 600 & 35.43 & 32.95 & 79.28 & 56.58 & 35.17 & 32.69 & 82.19 & 57.18 \\
\hline 700 & 36.88 & 34.40 & 74.96 & 56.74 & 34.44 & 31.96 & 85.18 & 57.34 \\
\hline \multirow[t]{2}{*}{800} & 34.54 & 32.06 & 83.11 & 56.83 & 37.05 & 34.57 & 77.20 & 57.58 \\
\hline & \multicolumn{4}{|c|}{ Chitosan } & \multicolumn{4}{|c|}{ CMC } \\
\hline $\mathbf{0 . 0 0}$ & 32.17 & 29.69 & 86.85 & 55.57 & 32.17 & 29.69 & 86.85 & 55.57 \\
\hline 100 & 34.39 & 31.91 & 81.36 & 56.16 & 34.48 & 32.00 & 81.28 & 56.22 \\
\hline 200 & 34.07 & 31.59 & 82.94 & 56.31 & 34.58 & 32.10 & 81.44 & 56.37 \\
\hline 300 & 35.59 & 33.11 & 78.78 & 56.59 & 35.40 & 32.92 & 79.61 & 56.65 \\
\hline 400 & 33.35 & 30.87 & 86.68 & 56.70 & 33.06 & 30.58 & 87.93 & 56.78 \\
\hline 500 & 34.90 & 32.42 & 82.61 & 57.04 & 34.70 & 32.22 & 83.11 & 56.99 \\
\hline 600 & 34.75 & 32.27 & 83.85 & 57.26 & 34.34 & 31.86 & 85.35 & 57.30 \\
\hline 700 & 34.97 & 32.49 & 83.85 & 57.48 & 35.63 & 33.15 & 82.02 & 57.59 \\
\hline 800 & 37.45 & 34.97 & 76.21 & 57.68 & 39.86 & 37.38 & 68.64 & 57.84 \\
\hline
\end{tabular}

\subsection{Effect of Electrode Rotation on the Rate of Polishing}

The effect of the speed of rotation on the electropolishing rate can also be used to determine whether the electropolishing process is diffusion or chemically controlled process. If the limiting current density increases by increasing the speed of rotation and decrease by increasing concentration of natural polymers, then the reaction is diffusion controlled. However, if the limiting current is independent of the rotation, so the reaction is likely to be chemically controlled. The angular velocity, $\omega$, is given by: 
figure 7 shows the relation between the limiting current density and the angular velocity to a power0.7 at $25^{\circ} \mathrm{C}$ for different concentration of Cellulose as example Straight lines were obtained and the limitingcurrent density increases by increasing rotation and decrease by increasing concentration of natural polymers, which indicates that the electropolishing process of carbon steel is diffusion controlled reaction. The diffusion coefficient of $\mathrm{Fe}^{2+}$ ions, $\mathrm{D}$, in different solutions was determined from the values of limiting current density, as shown in Table 5, using Eisenberg equation [33].

$I_{l}=\operatorname{kn~F~C~} d_{b} d^{-0.3} v^{0.344} D^{0.644} U^{x}$

Where $\mathrm{k}=0.097$ and $\mathrm{x}=0.7, \mathrm{n}$ is the number of electrons involved in process, $\mathrm{F}$ is Faraday's constant, $\mathrm{U}$ is the peripheral velocity $=\omega \mathrm{r}$ in $\mathrm{cm} \mathrm{rad} \mathrm{s}^{-1}(\mathrm{r}$ is the radial distance in $\mathrm{cm})$ or $\mathrm{U}=2 \pi \omega \mathrm{r}$ in $\mathrm{cm} \mathrm{s}^{-1}, \mathrm{~d}$ is the characteristic length for the rotating cylinder in $\mathrm{cm}$, and $v$ is the kinematic viscosity $(v=\eta / \rho, \eta$ is the viscosity in $\mathrm{g} \mathrm{cm}^{-1} \mathrm{~s}^{-1}$ and $\rho$ is the density in $\mathrm{g} \mathrm{cm}^{-3}$ ).

The diffusion coefficient ; $\mathrm{D}$, of $\mathrm{Fe}^{2+}$ ions in solutions containing organic compounds decreases due to the increase in the interfacial viscosity , $\eta$ in accordance with Stokes- Einstein equation [34]. The present results agree with the polar graphic studies conducted in solution containing surfactants and also solution containing organic solvent, where it was found that the diffusion current decreases in the presence of surfactant and organic solvent [34].

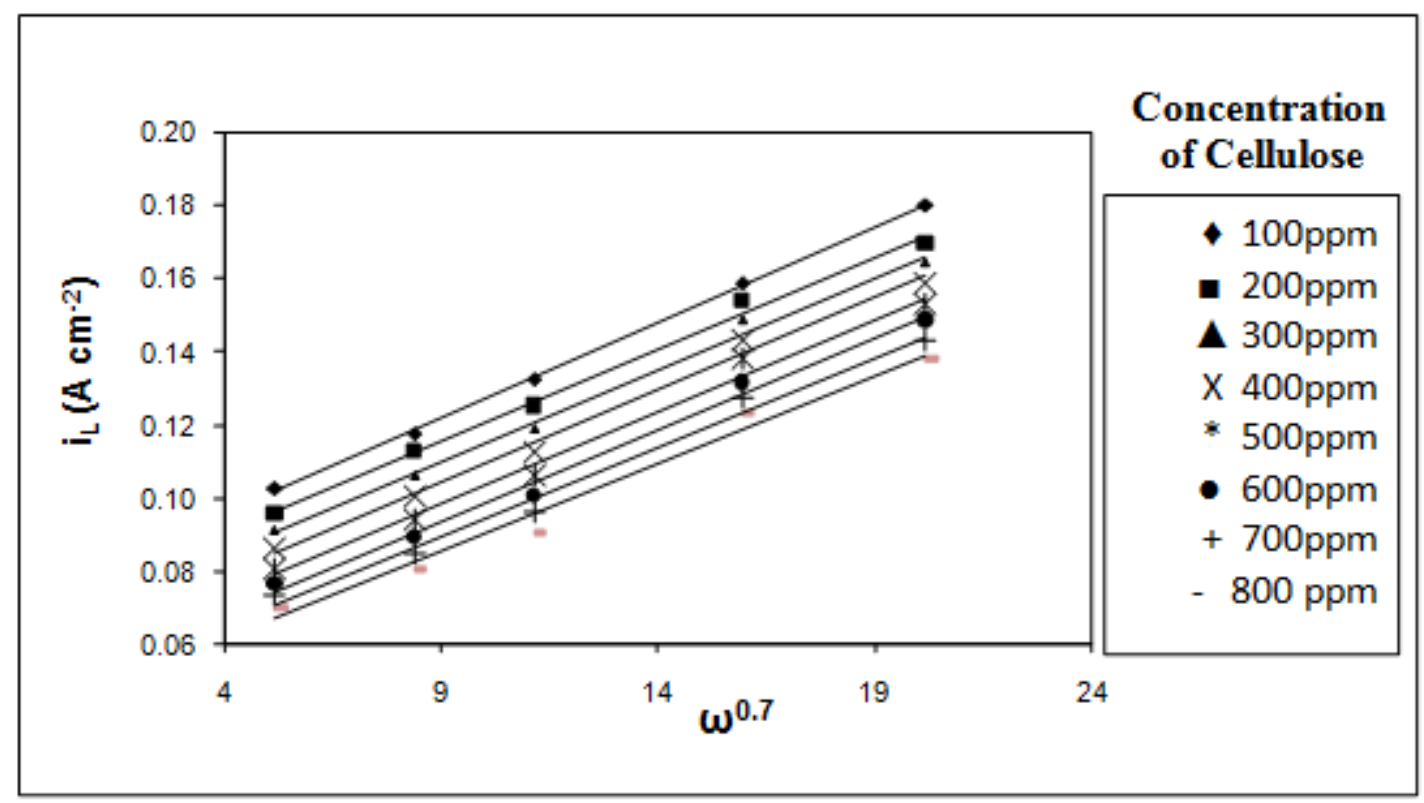

Figure7. Shows the relation between the limiting current density and the angular velocity to a power0.7 at $25^{\circ} \mathrm{C}$ for different concentration of Cellulose

\subsection{Data Correlation}

The mass transport to an inner rotating cylinder electrode in turbulent flow system may be described by empirical dimensionless formula.

$\mathbf{S h}=\mathbf{a} \mathbf{S c}^{\mathbf{c}} \mathbf{R e}^{\mathbf{b}}$

Where Sh, Re and Sc are the Sherwood $(\mathrm{Sh}=\mathrm{kl} / \mathrm{D}), \mathrm{k}$ is mass transfer coefficient, $\mathrm{cm} \mathrm{sec}^{-1}(\mathrm{k}=$ $\mathrm{I} / \mathrm{zFC} \mathrm{b}_{\mathrm{b}}$ where $\mathrm{C}_{\mathrm{b}}$ is bulk concentration, $\mathrm{z}$ is the valance, $\mathrm{F}$ is Faraday's constant in coulomb), 1 is length of cylinder, $\mathrm{cm}$ and $\mathrm{D}$ is diffusion coefficient, $\mathrm{cm}^{2} \mathrm{sec}^{-1}$, Reynolds $(\mathrm{Re}=1 \mathrm{U} / v), v$ is kinematic viscosity, $\mathrm{cm}^{2} \sec ^{-1}$ and $\mathrm{U}$ is rotation velocity $=\omega \mathrm{r}, \mathrm{cm} \mathrm{sec}^{-1}$, and Schmidt $(\mathrm{Sc}=v / \mathrm{D})$ numbers, respectively and $\mathrm{a}$ and $\mathrm{b}$ are empirical constants, $\mathrm{c}=0.33$ indicating forced convection regime [35]. By plotting $\log \left(\mathrm{Sh} / \mathrm{Sc}^{0.33}\right)$ against $\log (\mathrm{Re})$, a straight line was obtained its slope gave the constant $\mathrm{b}$ while the intercept gives the constant a. Figure.(8) shows the mass transfer correlation for all parameters used for gelatin as example. We found that the data can be correlated by the following equations: 
Electropolishing of Carbon Steel in Presence of Some Natural Polymers under Natural and Forced Convection Conditions

\begin{tabular}{|l|l|l|}
\hline 1. & For blank solution & $\mathrm{Sh}=0.2799 \mathrm{Re}^{0.719} \mathrm{Sc}^{0.33}$ \\
\hline 2. & For starch & $\mathrm{Sh}=0.2891 \mathrm{Re}^{0.715} \mathrm{Sc}^{0.33}$ \\
\hline 3. & For gelatin & $\mathrm{Sh}=0.2871 \mathrm{Re}^{0.716} \mathrm{Sc}^{0.33}$ \\
\hline 4. & For agar & $\mathrm{Sh}=0.2884 \mathrm{Re}^{0.715} \mathrm{Sc}^{0.33}$ \\
\hline 5. & For chitosan & $\mathrm{Sh}=0.2951 \mathrm{Re}^{0.714} \mathrm{Sc}^{0.33}$ \\
\hline 6. & For arabic gum & $\mathrm{Sh}=0.2931 \mathrm{Re}^{0.714} \mathrm{Sc}^{0.33}$ \\
\hline 7. & For cellulose acetate & $\mathrm{Sh}=0.3041 \mathrm{Re}^{0.771} \mathrm{Sc}^{0.33}$ \\
\hline 8. & For cellulose & $\mathrm{Sh}=0.2944 \mathrm{Re}^{0.714} \mathrm{Sc}^{0.33}$ \\
\hline 9. & For CMC & $\mathrm{Sh}=0.2999 \mathrm{Re}^{0.712} \mathrm{Sc}^{0.33}$ \\
\hline
\end{tabular}

In our present study a forced convection mechanism is obtained which agrees very well with similar relationships reported before [33, 36, and 37].

Table5. The general correlation of free convection mass transfer for 100 ppm of Cellulose as example using rotating cylinder electrode at $25^{\circ} \mathrm{C}$

\begin{tabular}{|c|c|c|c|c|c|c|c|c|c|c|}
\hline rpm & $\begin{array}{r}I_{L} \\
\left.\left(A^{-2}\right)^{-2}\right)\end{array}$ & $\begin{array}{c}v \\
\left(\mathrm{~cm}^{2} \mathrm{~s}^{-1}\right)\end{array}$ & $\underset{\left(\mathrm{cm} \cdot \mathrm{s}^{-1}\right)}{U}$ & $\begin{array}{l}K * 10^{-5} \\
\left(\mathrm{~cm}^{2} \cdot \mathrm{s}^{-1}\right)\end{array}$ & $\begin{array}{l}\text { D*10 } 10^{-7} \\
\left(\mathrm{~cm}^{2} \cdot \mathrm{s}^{-1}\right)\end{array}$ & Sh & Sc & $\operatorname{Re}$ & $\operatorname{logSh} / \mathrm{Sc}^{0.33}$ & $\log R e$ \\
\hline 100 & 0.10292 & \multirow{5}{*}{0.0182} & 5.236 & 6.666 & 3.275 & $\begin{array}{l}610 . \\
5155\end{array}$ & 55565.31059 & 287.69148 & 1.21991 & 2.45893 \\
\hline 200 & 0.11777 & & 10.47 & 7.628 & 1.901 & $\begin{array}{l}1203 . \\
75081\end{array}$ & 95739.77497 & 575.38324 & 1.43678 & 2.75996 \\
\hline 300 & 0.13263 & & 15.71 & 8.590 & 1.471 & $\begin{array}{l}1751 . \\
55247\end{array}$ & 123706.33128 & 863.075 & 1.56293 & 2.93605 \\
\hline 500 & 0.15915 & & 26.18 & 10.31 & 1.121 & $\begin{array}{l}2759 . \\
25645\end{array}$ & 162397.59552 & 1438.45824 & 1.7213 & 3.1579 \\
\hline 700 & 0.18037 & & 36.65 & 11.68 & 0.944 & $\begin{array}{l}3711 . \\
74581\end{array}$ & 192756.08362 & 2013.84148 & 1.82553 & 3.30403 \\
\hline
\end{tabular}

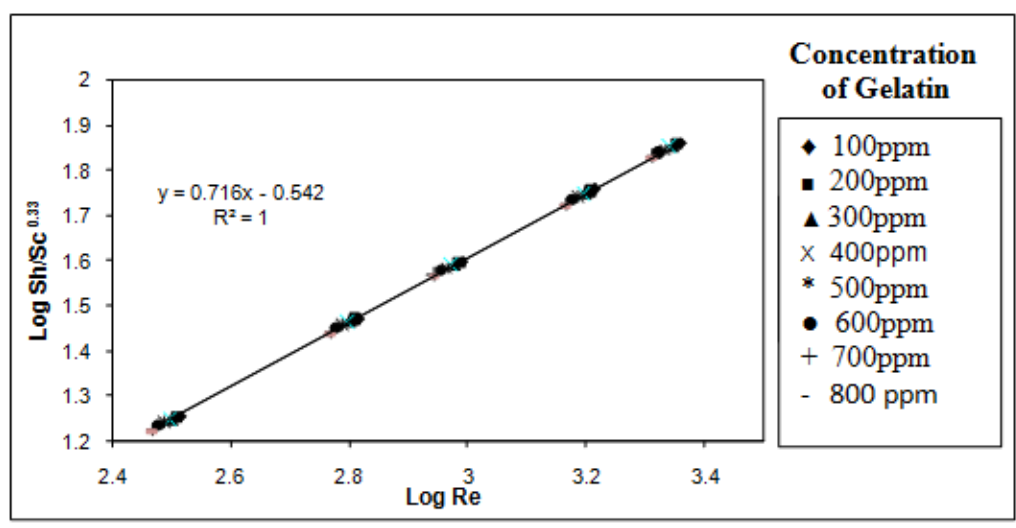

Figure8. The mass transfer correlation for Gelatin

\subsection{Application of Natural Polymers on Corrosion Control}

Concentration of $\mathrm{Fe}^{+2}(\mathrm{ppm})$ in case of presence and absence of natural polymers are measured. we found that as concentration of natural polymer increases, the positively iron ions $\mathrm{Fe}^{+2}$ (ppm) will decrease as shown in table (6) and figure (9). So this effect will make the ability to control the corrosion in carbon steel and give an indication for these polymers as a good inhibitors.

Table6. Values of $\mathrm{Fe}^{+2}$ (ppm) for different concentrations of natural polymers as corrosion inhibitors at $298 \mathrm{~K}$

\begin{tabular}{|c|c|c|c|c|c|c|c|c|}
\hline \multirow{2}{*}{$\begin{array}{c}\mathbf{C} \\
\mathbf{p p m})\end{array}$} & Starch & Gelatin & Agar & Chitosan & $\begin{array}{l}\text { Arabic } \\
\text { gum }\end{array}$ & $\begin{array}{l}\text { Cellulose } \\
\text { acetate }\end{array}$ & Cellulose & CMC \\
\hline $\mathbf{0}$ & 987.4 & 987.4 & 987.4 & 987.4 & 987.4 & 987.4 & 987.4 & 987.4 \\
\hline $\mathbf{1 0 0}$ & 630.6 & 870.0 & 788.9 & 279.3 & 495.03 & 88.60 & 440.7 & 151.1 \\
\hline $\mathbf{2 0 0}$ & 606.9 & 822.7 & 760.1 & 230.06 & 474.7 & 79.58 & 420.4 & 132.2 \\
\hline $\mathbf{3 0 0}$ & 570.32 & 781.0 & 740.8 & 198.97 & 451.5 & 70.06 & 370.3 & 120.5 \\
\hline $\mathbf{4 0 0}$ & 530.87 & 740.7 & 719.6 & 166.13 & 420.8 & 63.99 & 340.96 & 109.8 \\
\hline $\mathbf{5 0 0}$ & 496.23 & 709.0 & 697.8 & 134.09 & 398.06 & 55.48 & 299.1 & 100.2 \\
\hline $\mathbf{6 0 0}$ & 450.98 & 688.9 & 670.3 & 110.76 & 360.87 & 46.01 & 270.7 & 90.05 \\
\hline $\mathbf{7 0 0}$ & 410.03 & 634.6 & 605.1 & 90.94 & 290.07 & 35.72 & 219.08 & 70.30 \\
\hline $\mathbf{8 0 0}$ & 370.55 & 591.1 & 565.9 & 75.81 & 233.19 & 20.41 & 170.11 & 50.77 \\
\hline
\end{tabular}




\section{$298 \mathrm{~K}$}

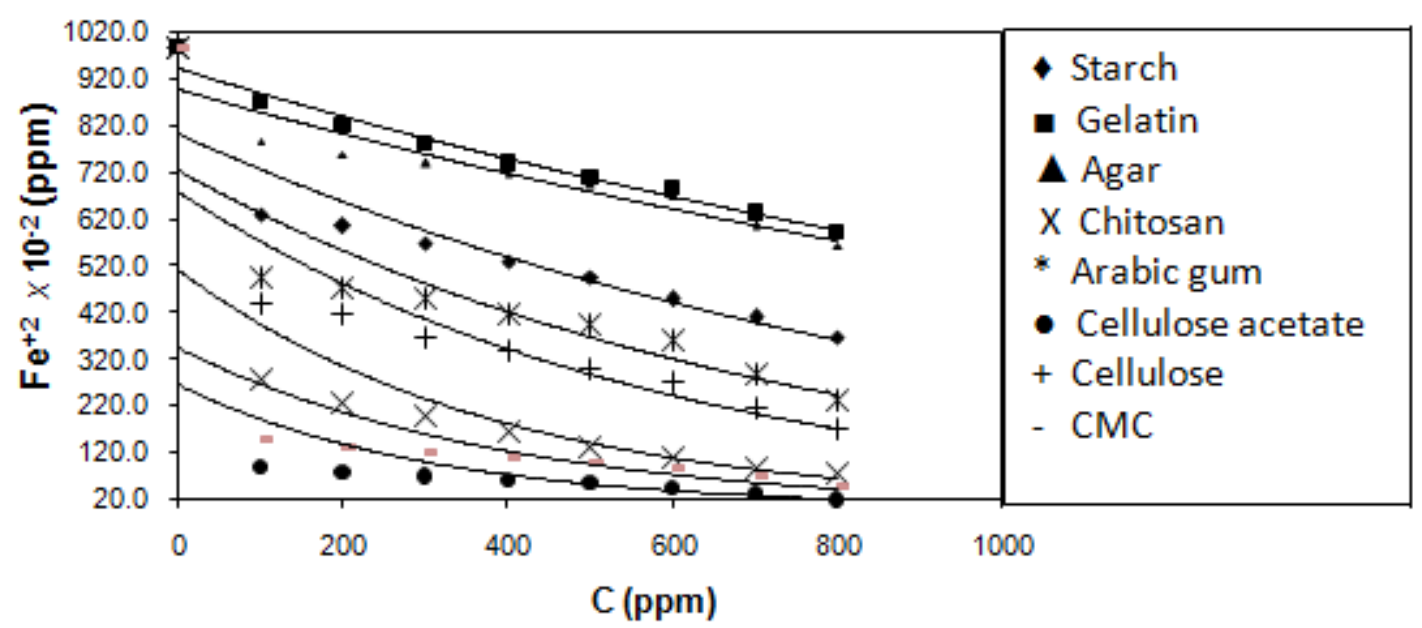

Fig9.

\section{Conclusions}

The rate of Electropolishing of carbon steel in $\mathrm{H}_{3} \mathrm{PO}_{4}$ increases by increasing temperature, due to the increase of mass transfer, but decreases in the presence of natural polymers by amount ranging from 3.87 to $61.54 \%$ depending on polymer concentration and polymer structure.

- The adsorption of inhibitors on carbon steel surface obeys Florry-Huggins and kinetic adsorption isotherm for all studied compounds.

- The activation energy values for carbon steel Electropolishing in the inhibited solutions are higher than that for the uninhibited solutions indicating good inhibitor characteristics.

- Rotating cylinder electrode (RCE) is studied, the rate of Electropolishing increases by increasing the speed of rotation, which indicates that the reaction is a diffusion-controlled one.

- The dimensionless groups Sh (Sherwood number), Sc (Schmidt number) and Re (Reynolds number) were calculated for steel and the relations between them were given.

- In addition, we study the surface morphology for steel. The optimum conditions to obtain dense microstructure in absence and presence of natural polymers which improvement the polishing obtain.

\section{REFERENCES}

[1] P.A. Jacquet. Nature. 135 (3426), 1076, (1935).

[2] Chemical and Electrolytic Polishing, in ASM Handbook. ASM International. p. 281-293, (2004).

[3] W.C. Elmore, Electrolytic Polishing. Journal of Applied Physics. 10, 724 (1939); 11, 799 (1940).

[4] E. M. Sherif and S. M. Park, J. Electrochem. Soc. 152, 428 (2005).

[5] A. A. Elwarraky, H. A. Elshayeb and E. M. Sherif, Anti- Corros-Methods Mater. 51, 52 (2004).

[6] Jun-E. Qu, Xingpeng Guo and Zhenyn Chen, Matter. Chemistry Phys. 93, 388 (2005).

[7] N. Bellakhal and M. Dachraoui, Mater. Chem. Phys. 85, 366 (2004).

[8] M. Kending and S. Jeanjaquat, J. Electrochem. Soc., 149, 1347 (2002).

[9] G.H.Sedahmed, B.A.Abdel-Naby and A.Abdel-Khalik, corrosion science 17 (1977) 865.

[10] T.Poornima, J.Nayak and A.N.Shetty, corrosion science 53 (2011) 3688-3696.

[11] El Sayed M. Sherif, Surf. Sci. Appl. 252, 8615 (2006).

[12] H. Y. Ma, C. Yang, B. S. Yin, G.y.Li, S. H. Chen and J. L. Luo, J. Appl. Surf. Sci., 218, 143 (2003).

[13] M. A. Elmorsi and A. M. Hassanein, Corros. Sci., 43, 2337 (1999).

[14] M. Scendo, D. Poddebnia and J. Malyszko, J. Appl. Electrochem., 33, 287 (2003).

[15] El-Sayed M. Sherif and A. M. El Shamy, Mostafa M. Ramla and Ahmed O. H. El Nazhawy, Matterials chemistry and physics, 102, 231 (2007). 
[16] C.R. Wilke, Eiesenberg M. and Tobias C.W., J. Electrochem. Soc. 100, (1953), 513.

[17] N.M. El-Mallah, , A.M. Ahmed, L.F. Gado, J. Dispersion Sci. Technol., 31, (2010), 1579

[18] I.Z. Selim, K. M. ElSobki, A. E. Kheder and H. M. A. Soliman, Bull. Electrochem. Ind., 16, 315 (2000).

[19] A. Einstein, Royal Soc. London, 106, (1924), 724.

[20] Y. K. Agrawal, J. D. Talati, M. D. Shah, M. N. Desai and N. K. Shah, Corrosion Science, 46,633 (2004).

[21] Helena Otmacic, Ema Stupnisek-Lisac, Electrochimica Acta,48,985 (2003).

[22] M.A. Quraishi and R. Sardar, Bull. Electrochem., 18, (2002), 515.

[23] A.M. Abdel-Gaber, B.A. Abd El-Nabey, I.M. Sidahmed, A.M. El-Zayady, M. Saadawy, Corr. Science,48, (2004), 2765.

[24] E. E. Ebenso, P. Cokafor, O. E. offiong, BI. Ita, U. J. Ibok and U, J. Ekpe, Bull. Electrochem., 17,459 (2001).

[25] L.B. Tang,G.N.Mu and G.H.Liu, Corros. Sci., 45, 2251 (2003).

[26] J.Flis and T.Zakro Czymski, J. Electrochem.Soc., 143, 2458 (1996).

[27] N. Hackerman, A.C. Makrides, In. Eng. Chem., 46, (1964), 323.

[28] E. A. Noor, Mater. Chem. Phys. 114, 533, (2009).

[29] R. D. Kaushik Rathi, Rajdeep Malik, Jaspal Singh and Manila, Int. J. Chem Tech Res. 6(5), 3122, (2014).

[30] H. Ashassi - Sorkhabr, B. Shabani and B. Aligholipour, Appli. Surf. Sci. 239, 154, (2005).

[31] G. Owusu, Ph.D thesis, Dep. Of Metals and Material Engineering, Univ. of British Columbia, (1993).

[32] M. Bouklah, N. Benchat, A. Aounit, B. Hammouti, M. Benkaddout, M. Lagreniee, H. Vezin and F. Bentiss, Prog. Org. Coat. 51, 118, (2004).

[33] A. M. Ahmed, E. A. Hamed, A. A. El-Bardan and E. F Saad Alex Eng. J. Univ. 28, 577 (1989).

[34] M. Eisenbery, C.W.Tobias and C.R. Wilke, J. Electrochem. Soc., 101, 306 (1954).

[35] Gehan M. El-Subruiti and A.M. Ahmed, Portugaliae electrochimica Acta, 20, 151, (2002).

[36] D.R.Gabe and F.C.Walsh, J. App. Electrochem., 13, 3 (1983).

[37] H. H. Abdel-Rahman and M. A. Darweesh, Egypt. J. Chem., 49: 19 (2006).

Citation: H. F.M. El-shamy, "Electropolishing of Carbon Steel in Presence of Some Natural Polymers under Natural and Forced Convection Conditions", International Journal of Advanced Research in Chemical Science (IJARCS), vol. 4, no. 6, pp. 1-12, 2017. http://dx.doi.org/10.20431/2349-0403.0406001

Copyright: (C) 2017 Authors. This is an open-access article distributed under the terms of the Creative Commons Attribution License, which permits unrestricted use, distribution, and reproduction in any medium, provided the original author and source are credited. 